\title{
Incidental thyroid carcinomas in patients operated on for benign thyroid pathology, are there preoperative factors suggesting a higher risk? \\ ECE 2013
}

Hospital de Basurto

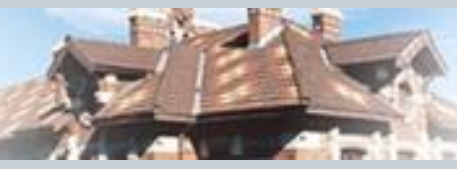

P.538

\section{Paja, ${ }^{1}$ A. Ugalde, ${ }^{2}$ B. Barrrios, A. Oleaga, L. Calles, C. Moreno, E. Ugarte. Endocrinology,} 1 Pathology, ${ }^{2}$ Endocrine Surgery. Hospital de Basurto. Bilbao.

The discovery of incidental thyroid carcinomas (ITC) in patients undergoing surgery for a benign disease range between 3 and $16 \%$ of cases. During years, patients with hyperthyroidism were considered protected by TSH suppression (as TSH favors the development of thyroid cancer). Instinctively, thyroid size might be a predictive factor due to the excess of thyroid tissue prone to mutations. The knowledge of determining factors foretelling the presence of undiagnosed thyroid carcinomas would be interesting since these tumours not always have an indolent course.

We evaluate retrospectively 568 patients with total thyroidectomy operated on for reasons other than malignancy between 2005 and 2011. We compare demographic and clinical characteristics between two groups: patients without ITC and patients with discovery of ITC in final pathological study of thyroid. Analysis included age, sex distribution, preoperative hyperfunction, pathology of benign tissue (adenoma vs hyperplasia/inflammation), and thyroid size measured by weight.

ITC was discovered in 79 of 568 operated patients (13,9\%). Average age in patients with ITC was $54.6 \pm 14.6 y$ while $55,1 \pm 12.1$ in non-ITC patients $(\mathrm{p}=0,75)$. Mean weight in thyroid harboring ITC (54.2 $\pm 43 \mathrm{~g})$ was significant lesser than in non malignant glands $(76.9 \pm 76.2 \mathrm{~g} ; \mathrm{p}=0.011)$. There were 84 hyperthyroid patients, 10 in the ITC group, without significant difference $(p=0,73)$. Final diagnosis included 152 adenomas and 416 hyperplasic or inflammatory glands, without difference between both groups $(p=0,79)$. Sex didn't influence in the detection of ITC, with 9 cases in 69 males, and 70 in 499 females.

\begin{tabular}{|l|c|c|c|c|c|}
\hline & $\begin{array}{c}\text { Age (years) } \\
\text { Mean (SD) }\end{array}$ & $\begin{array}{c}\text { Gland weight } \\
\text { Mean (SD) g }\end{array}$ & $\begin{array}{c}\text { Sex } \\
\text { Males }\end{array}$ & $\begin{array}{c}\text { Hyperthyroidism } \\
\text { (\%) }\end{array}$ & Adenomas \\
\hline $\begin{array}{l}\text { ITC } \\
\text { n: 79 }\end{array}$ & $\begin{array}{c}54.6 \\
(14.6)\end{array}$ & $\begin{array}{c}54.2 \\
(43)\end{array}$ & $12.3 \%$ & $15.1 \%$ & $26.6 \%$ \\
\hline $\begin{array}{l}\text { No ITC } \\
\text { n: 489 }\end{array}$ & $\begin{array}{c}55.1 \\
(12)\end{array}$ & $\begin{array}{c}76,9 \\
(76.3)\end{array}$ & $11.4 \%$ & $11.4 \%$ & $27.8 \%$ \\
\hline $\mathbf{p}$ & $\begin{array}{c}0.75 \\
\text { Student }\end{array}$ & $\begin{array}{c}\mathbf{0 . 0 1 1} \\
\text { Mann-Whitney }\end{array}$ & $\begin{array}{c}0.83 \\
\text { Chi-square }\end{array}$ & $\begin{array}{c}0.73 \\
\text { Chi-square }\end{array}$ & $\begin{array}{c}\text { O.79 } \\
\text { Chi-square }\end{array}$ \\
\hline
\end{tabular}

The incidence of ITC in our thyroidectomized patients is $13,9 \%$, similar to previously published. Neither age nor sex were useful clues to suspect ITC. Hyperfunction doesn't protect from ITC. Adjacent pathology is not relevant to the appearance of ITC in an operated benign thyroid. The only parameter associated with more prevalent ITC was a lesser weight of the dissected thyroid. 